\title{
Acylated Ghrelin, Growth Hormone and IGF-1 Levels in the Cord Blood of Small for Gestational Age Newborns
}

\author{
Nastaran Khosravi, ${ }^{1}$ Farhad Abolhasan Choobdar, ${ }^{1}$ Nasrin Khalesi, ${ }^{1}$ Arash Bordbar, ${ }^{1}$ Bagher Larijani, ${ }^{2}$ \\ Zahra Arab, ${ }^{3}$ and Mitra Nourbakhsh ${ }^{3,4, *}$ \\ ${ }^{1}$ H. Aliasghar Hospital, Iran University of Medical Sciences, Tehran, IR Iran \\ ${ }^{2}$ Endocrinology and Metabolism Research Center, Endocrinology and Metabolism Research Institute, Tehran University of Medical Sciences, Tehran, IR Iran \\ ${ }^{3}$ Metabolic Disorders Research Center, Endocrinology and Metabolism Molecular-Cellular Sciences Institute, Endocrinology and Metabolism Research Institute, Tehran \\ University of Medical Sciences, Tehran, IR Iran \\ ${ }^{4}$ Department of Biochemistry, School of Medicine, Iran University of Medical Sciences, Tehran, IR Iran \\ "Corresponding author: Mitra Nourbakhsh, M.Sc., Ph.D, Department of Biochemistry, School of medicine, Iran University of Medical Sciences, 1417613151, Tehran, IR Iran. Tel/Fax: \\ +98-21 88622742, +98 9122874740, E-mail: nourbakhsh.m@iums.ac.irmitra.nourbakhsh@gmail.com
}

Received 2016 October 05; Accepted 2016 October 09.

\begin{abstract}
Background: Ghrelin is a pleiotropic hormone that regulates feeding and energy balance and stimulates growth hormone release. Ghrelin also exerts developmental and organizational effects during prenatal life.

Objectives: The aim of this study was to determine ghrelin levels in cord blood of small for gestational age (SGA) infants and its association with GH (growth hormone) and IGF-1 levels (insulin-like growth factor-1).

Methods: Cord blood sample was obtained from 31 SGA and 25 appropriate for gestational age (AGA) infants. Acylated ghrelin, GH, and IGF-1 levels were measured by enzyme-linked immunosorbent assay.

Results: No significant differences were observed in ghrelin and GH concentrations between SGA and AGA infants. However, IGF-1 levels were significantly lower in SGA infants. Cord blood ghrelin was negatively correlated with the infants' birth weight $(r=-0.33$, $\mathrm{P}=0.013)$; on the other hand, IGF-1 level was positively correlated with birth weight $(\mathrm{r}=0.43, \mathrm{P}=0.002)$.

Conclusions: IGF-1 has the most significant effect on intrauterine growth. Acylated ghrelin is detectable in cord blood and correlated with birth weight, suggesting a role in intrauterine development, but its level is not affected by intrauterine growth retardation.
\end{abstract}

Keywords: Ghrelin, Growth Hormone (GH), IGF-1, Small for Gestational Age (SGA), Appropriate for Gestational Age (AGA), Intrauterine Growth

\section{Background}

Ghrelin is a 28-amino-acid peptide that is primarily secreted by gastric mucosal cells and plays a key role in appetite regulation and energy balance. It was discovered through its effect on growth hormone (GH) secretion, and thus was presumed to be effective in growth (1-3). Several other activities have also been attributed to ghrelin $(4,5)$. In addition to its effects on GH secretion, ghrelin has also been shown to stimulate appetite and induce adiposity (6).

Small for gestational age (SGA) newborn infants showed reduced growth during the intrauterine period, which might have occurred because of fetal, maternal or environmental factors. These infants have low levels of $\mathrm{GH}$ after birth in response to nutritional deficiency before birth (3). Although most of these infants may catch up growth rapidly after birth, various patterns of weight gain is observed in infancy, which may be related to feeding and fasting $(2,4)$. There is a strong association between very low birth weight and infant mortality, which may be due to extreme fetal growth retardation (7).

Considering the important relationship between nutrition and growth and the orexigenic function of ghrelin, this hormone seems to be closely associated with postnatal growth. Presence of ghrelin in umbilical cord has been demonstrated, but few studies have measured ghrelin levels in the umbilical cord of newborn infants $(8,9)$.

With the assumption that umbilical cord ghrelin level, as well as GH and IGF-1 levels can indicate their levels during intrauterine period, the aim of this study was to determine whether cord blood ghrelin, GH and IGF-1 levels are different in SGA newborn infants compared to appropriate for gestational age (AGA) newborn infants.

\section{Methods}

\subsection{Participants}

In this cross-sectional study, 56 newborn infants born at Akbarabadi hospital in Tehran were included. Infants 
whose birth weight was below the 10th percentile for gestational age were defined as SGA, and those with birth weight between 10th and 90th percentile were defined as AGA. According to this definition, the infants were divided into two groups: 31 infants with SGA, and 25 with AGA. Both groups were included consecutively and by convenience sampling.

All the studied infants were devoid of any congenital abnormalities, and had no history of maternal chronic diseases such as diabetes, autoimmune diseases, pregnancyinduced hypertension and pre-eclampsia. Newborns were from third gestation or less, and the mothers did not smoke nor had any kinds of addiction.

Demographic data, underlying conditions and 5th minute Apgar score were recorded. The height and weight of each infant were accurately measured and recorded in the checklist.

The Ethics Committee of Tehran University of Medical Sciences approved the study, and written informed consent was obtained from all mothers before cord blood sampling. All the procedures were in accordance with the ethical standards of the responsible committee on human experimentation (institutional and national) and with the Helsinki Declaration of 1975, as revised in 2000.

\subsection{Biochemical Assays}

Venous cord blood was collected immediately after clamping the umbilical cord in EDTA tubes and kept at $4^{\circ} \mathrm{C}$ before centrifugation. For ghrelin determination, PMSF was added to the final concentration of $0.1 \mathrm{mg} / \mathrm{mL}$ as a protease inhibitor. After centrifugation at $4^{\circ} \mathrm{C}$, the separated plasma was acidified with $\mathrm{HCl}$ to a final concentration of $0.05 \mathrm{~N}$. All the samples were stored at $80^{\circ} \mathrm{C}$ until later analysis. Acylated ghrelin was measured, using a commercial ELISA kit (DRG, USA), with intra- and inter-assay CV of $6.3 \%$ and $5.4 \%$, respectively. Serum GH and IGF-1 were measured by chemiluminescence sandwich assay, using directly coated magnetic microplates (Diasorin Ltd, UK).

\subsection{Statistical Analysis}

The differences in variables between groups were compared, using student's t test. The chi-square test was used to compare nominal variables between groups, and student's t test was used for numeric variables. The relationship between different parameters was determined, using Pearson's correlation. All the statistical analyses were performed, using SPSS Version 16 (SPSS Inc., Chicago, IL, USA). P value $<0.05$ was considered statistically significant.

\section{Results}

The anthropometric and biochemical characteristics of the neonates and their mothers are presented in Table 1. Overall, cord plasma ghrelin concentrations were 104.6 \pm $87 \mathrm{pg} / \mathrm{mL}$ (Range 12.58 - $508.54 \mathrm{pg} / \mathrm{mL}$ ). As demonstrated in Table 1, although there was a trend towards higher ghrelin concentration in SGA infants, no significant difference was found between the two groups in ghrelin concentration. Similarly, GH concentration was not statistically different between SGA and AGA infants. IGF-1 level was significantly lower in SGA infants compared to AGA group. No significant differences were observed between male and female infants in ghrelin, GH, and IGF-1 levels (Table 2).

Cord blood ghrelin concentration was negatively correlated with the infants' birth weight $(r=-0.33, P=0.013)$. On the other hand, IGF-1 showed a significant positive correlation with birth weight $(\mathrm{r}=0.43, \mathrm{P}=0.002)$. Nevertheless, no relationship was found between $\mathrm{GH}$ and birth weight $(P=0.4)$. The relationship between $G H$, IGF-1, and acylated ghrelin was investigated and found to be nonsignificant. Mothers' weights and their correlations with GH, IGF-1, and ghrelin were also investigated, but no significant correlations were observed between them.

\section{Discussion}

The results of this study revealed that acylated ghrelin is correlated with birth weight, and it is slightly but not significantly higher in SGA infants. Among the studied parameters, which are all effective in growth, IGF-1 exerts the most dramatic influence on growth considering its low concentration in SGA infants, and its strong correlation with birth weight.

Ghrelin has previously been shown to be elevated in anorexia and children with poor appetite (10) and diminished in obesity, playing a role in the regulation of energy homeostasis; thus, it is suggested that ghrelin represents the chronic nutritional status $(11,12)$. The cord blood ghrelin concentrations in SGA infants, compared to healthy newborns, have been reported in a few studies $(8,12,13)$.

All these studies reported that cord blood ghrelin concentrations of SGA infants are greater than those of AGA infants, and it was suggested that ghrelin is affected by nutritional status during the fetal life. However, these studies have investigated total ghrelin levels despite the fact that acylated form of the ghrelin is the active form of the hormone, and acylation is mandatory for the biologic effects of ghrelin on GH secretion and for binding to the receptor (14). Umbilical cord acylated ghrelin concentration is lower than maternal blood, and the placenta plays a role in the process of acylation (15). Thus, it is plausible that 
Table 1. Characteristics of the Neonates and Their Mothers ${ }^{\mathrm{a}}$

\begin{tabular}{|c|c|c|c|c|}
\hline & SGA (31) & AGA (25) & Total (56) & PValue \\
\hline $\operatorname{Sex}(M / F)$ & $15 / 16$ & $7 / 18$ & $22 / 34$ & 0.1 \\
\hline Gestational age, w & $35.5 \pm 3$ & $37.9 \pm 2.5$ & $36.6 \pm 3$ & $0.002^{\mathrm{b}}$ \\
\hline Birth weight, $\mathrm{g}$ & $2177.6 \pm 703.2$ & $3247.2 \pm 575.2$ & $2672.7 \pm 837.2$ & $<0.0001^{\mathrm{b}}$ \\
\hline Gravid & $1.9 \pm 1.3$ & $2.3 \pm 1.1$ & $2 \pm 1.2$ & 0.2 \\
\hline Maternal age, $y$ & $27.1 \pm 7$ & $29.6 \pm 5.9$ & $28.2 \pm 6.6$ & 0.1 \\
\hline APGAR 5 & $9.6 \pm 0.6$ & $9.9 \pm 0.3$ & $9.7 \pm 0.5$ & 0.06 \\
\hline Ghrelin, pg/mL & $121.26 \pm 109.4$ & $83.9 \pm 40.2$ & $104.6 \pm 87$ & 0.08 \\
\hline GH, ng/mL & $49.6 \pm 40.3$ & $54.7 \pm 24.9$ & $51.8 \pm 34.2$ & 0.58 \\
\hline IGF-1, ng/mL & $32.2 \pm 32$ & $59.3 \pm 35.9$ & $44 \pm 36$ & $0.008^{\mathrm{b}}$ \\
\hline
\end{tabular}

Abbreviations: AGA, appropriate for gestational age; GH, growth hormone; IGF-1, insulin-like growth factor-1; SGA, small for gestational age.

${ }^{\mathrm{a}}$ Values are expressed as mean $\pm \mathrm{SD}$.

${ }^{\mathrm{b}}$ Significant difference.

Table 2. Comparison of the Levels of ghrelin, GH and IGF-1 between Female and Male Infants

\begin{tabular}{lccc}
\hline & Female (34) & Male (22) & PValue \\
\hline Ghrelin, pg/mL & $109.9 \pm 94.9$ & $96.3 \pm 74.7$ & 0.57 \\
GH, ng/mL & $56.2 \pm 32.6$ & $45.2 \pm 36.4$ & 0.27 \\
IGF-1, ng/mL & $49.3 \pm 36.9$ & $35.9 \pm 33.9$ & 0.2 \\
\hline
\end{tabular}

the acylated ghrelin changes may be different from those of total ghrelin. Iniguez et al. investigated the serum levels of ghrelin in SGA and AGA infants after fasting and intravenous injection of glucose and found that after fasting, serum levels of ghrelin were not different between the SGA and AGA groups (16).

IGF-1 is one of the main factors responsible for regulating the fetal growth (17). In this study, IGF-1 levels were found to be significantly lower in SGA infants compared to AGA newborns. Consistent with our findings, Orbak et al. have also demonstrated that IGF-1 levels are significantly diminished in SGA neonates (18). This study revealed a significant positive correlation between IGF-1 and birth weight in contrast to ghrelin, which was negatively correlated with birth weight. The levels of both of these hormones seem to be altered in response to nutritional status. Increased ghrelin level in anorexia is suggested to be a compensatory response to undernutrition (19). On the other hand, it has been shown that intake of proteins that are rich in essential amino acids is positively associated with serum IGF-1 (20) and although total calorie restriction does not affect IGF-1 levels, protein intake is a key determinant of circulating IGF-1 levels in humans (21).

Our study found that ghrelin, GH, and IGF-1 concentra- tions were similar in male and female infants. In SGA infants, these hormones were not different in the two genders, but in AGA group, GH of female infants was significantly higher than that of the male infants. Consistent with our findings, Chanoine et al. found no significant difference between male and female infants (22).

In conclusion, these results suggest that minimal increase in ghrelin levels could be the consequence of growth restriction, but it may be caused by significant reduction in IGF-1. Thus, IGF-1 may be a suitable target for managing intrauterine growth.

\section{Acknowledgments}

This study was financially supported by a grant (number: 1392-01-104-1617) from Endocrinology and Metabolism Research Institute, Tehran University of Medical Sciences.

\section{Footnote}

Conflict of Interest: The authors declare no conflict of interest.

\section{References}

1. Cunha SR, Mayo KE. Ghrelin and growth hormone (GH) secretagogues potentiate GH-releasing hormone (GHRH)-induced cyclic adenosine 3',5'-monophosphate production in cells expressing transfected GHRH and GH secretagogue receptors. Endocrinology. 2002;143(12):4570-82. doi: 10.1210/en.2002-220670. [PubMed: 12446584].

2. Luque RM, Kineman RD, Park S, Peng XD, Gracia-Navarro F, Castano JP, et al. Homologous and heterologous regulation of pituitary receptors for ghrelin and growth hormone-releasing hormone. Endocrinology. 2004;145(7):3182-9. doi: 10.1210/en.2003-1626. [PubMed: 15044357]. 
3. Veldhuis JD, Bowers CY. Integrating GHS into the Ghrelin System. Int J Pept. 2010;2010 doi: 10.1155/2010/879503. [PubMed: 20798846].

4. Peroni CN, Hayashida CY, Nascimento N, Longuini VC, Toledo RA, Bartolini P, et al. Growth hormone response to growth hormonereleasing peptide-2 in growth hormone-deficient little mice. Clinics (Sao Paulo). 2012;67(3):265-72. [PubMed: 22473409].

5. Casanueva FF, Camina JP, Carreira MC, Pazos Y, Varga JL, Schally AV. Growth hormone-releasing hormone as an agonist of the ghrelin receptor GHS-R1a. Proc Natl Acad Sci U S A. 2008;105(51):20452-7. doi: 10.1073/pnas.0811680106. [PubMed: 19088192].

6. Makino Y, Hosoda H, Shibata K, Makino I, Kojima M, Kangawa K, et al. Alteration of plasma ghrelin levels associated with the blood pressure in pregnancy. Hypertension. 2002;39(3):781-4. [PubMed: 11897763].

7. Rasmussen KM, Yaktine AL, Guidelines C, Board FN, Board on Children YF, Medicine I. Weight Gain During Pregnancy: Reexamining the Guidelines. Washington (DC): National Academies Press; 2010.

8. Onal EE, Cinaz P, Atalay Y, Turkyilmaz C, Bideci A, Akturk A, et al. Umbilical cord ghrelin concentrations in small- and appropriate-forgestational age newborn infants: relationship to anthropometric markers. J Endocrinol. 2004;180(2):267-71. [PubMed: 14765978].

9. Iniguez $\mathrm{G}$, Ong K, Pena V, Avila A, Dunger D, Mericq V. Fasting and post-glucose ghrelin levels in SGA infants: relationships with size and weight gain at one year of age. J Clin Endocrinol Metab. 2002;87(12):5830-3. doi: 10.1210/jc.2002-021206. [PubMed: 12466394].

10. Razzaghy-Azar M. Total and Acylated Ghrelin Levels in Children and Adolescents with Idiopathic Short Stature and Poor Appetite. Acta Endocrinologica. 2015;11(3):401-6. doi: 10.4183/aeb.2015.401.

11. Ariyasu H, Takaya K, Tagami T, Ogawa Y, Hosoda K, Akamizu T, et al. Stomach is a major source of circulating ghrelin, and feeding state determines plasma ghrelin-like immunoreactivity levels in humans. J Clin Endocrinol Metab. 2001;86(10):4753-8. doi: 10.1210/jcem.86.10.7885. [PubMed: 11600536].

12. Farquhar J, Heiman M, Wong AC, Wach R, Chessex P, Chanoine JP. Elevated umbilical cord ghrelin concentrations in small for gestational age neonates. J Clin Endocrinol Metab. 2003;88(9):4324-7. doi: 10.1210/jc.2003-030265. [PubMed: 12970305].

13. Kitamura S, Yokota I, Hosoda H, Kotani Y, Matsuda J, Naito E, et al. Ghrelin concentration in cord and neonatal blood: relation to fetal growth and energy balance. J Clin Endocrinol Metab. 2003;88(11):5473-7. doi: 10.1210/jc.2002-021350. [PubMed: 14602792].

14. Nass R, Gaylinn BD, Thorner MO. The role of ghrelin in GH secretion and GH disorders. Mol Cell Endocrinol. 2011;340(1):10-4. doi: 10.1016/j.mce.2011.03.021. [PubMed: 21459126].

15. Lanyi E, Varnagy A, Kovacs KA, Csermely T, Szasz M, Szabo I. Ghrelin and acyl ghrelin in preterm infants and maternal blood: relationship with endocrine and anthropometric measures. Eur J Endocrinol. 2008;158(1):27-33. doi: 10.1530/EJE-07-0410. [PubMed: 18166814].

16. Iniguez G, Roman R, Youlton R, Cassorla F, Mericq V. Ghrelin plasma levels in patients with idiopathic short stature. Horm Res Paediatr. 2011;75(2):94-100. doi: 10.1159/000317429. [PubMed: 20861603].

17. Gluckman PD. Clinical review 68: The endocrine regulation of fetal growth in late gestation: the role of insulin-like growth factors.J Clin Endocrinol Metab. 1995;80(4):1047-50. doi: 10.1210/jcem.80.4.7714063. [PubMed: 7714063].

18. Orbak Z, Darcan S, Coker M, Goksen D. Maternal and fetal serum insulin-like growth factor-I(IGF-I) IGF binding protein-3 (IGFBP-3), leptin levels and early postnatal growth in infants born asymmetrically small for gestational age.JPediatr Endocrinol Metab. 2001;14(8):1119-27. [PubMed: 11592569].

19. Soriano-Guillen L, Barrios V, Campos-Barros A, Argente J. Ghrelin levels in obesity and anorexia nervosa: effect of weight reduction or recuperation. J Pediatr. 2004;144(1):36-42. doi: 10.1016/j.jpeds.2003.10.036. [PubMed: 14722516].

20. Allen NE, Appleby PN, Davey GK, Kaaks R, Rinaldi S, Key TJ. The associations of diet with serum insulin-like growth factor I and its main binding proteins in 292 women meat-eaters, vegetarians, and vegans. Cancer Epidemiol Biomarkers Prev. 2002;11(11):1441-8. [PubMed: 12433724].

21. Fontana L, Weiss EP, Villareal DT, Klein S, Holloszy JO. Long-term effects of calorie or protein restriction on serum IGF-1 and IGFBP3 concentration in humans. Aging Cell. 2008;7(5):681-7. [PubMed: 18843793].

22. Chanoine JP, Yeung LP, Wong AC, Birmingham CL. Immunoreactive ghrelin in human cord blood: relation to anthropometry, leptin, and growth hormone. J Pediatr Gastroenterol Nutr. 2002;35(3):282-6. [PubMed: 12352514]. 